\title{
Clinical Evaluation of the Use of Mini- Implants to Replace Congenitally Absent Maxillary Lateral Incisors: A Short-Term Study
}

\author{
Muhammad Alharissy¹, Suleiman Dayoub² \\ ${ }^{\mathbf{1}}$ Research Assistant, Damascus University, College of Dentistry, Department of Periodontology, Damascus,SYRIA \\ ${ }^{2}$ Associate Professor, Damascus University, College of Dentistry, Department of Periodontology, Damascus,SYRIA
}

\section{Key Words}

Mini-Implant Replaced Maxillary Lateral Incisor

\begin{abstract}
Aim: The aim of this study was to evaluate the treatment outcome of immediately restored mini-implants with a diameter of $2.5 \mathrm{~mm}$ one year after their use for rehabilitation of congenitally absent maxillary lateral incisors.

Methodology: A total of 30 mini-implants (narrow ridge 2.5) were inserted in 23 patients ( 13 females, 10 males) with a mean age of 21.6 years (range: 16-38 years) at the implant center of Damascus University. The implants replaced congenitally absent maxillary lateral incisors. All implants were immediately restored with a nonfunctional provisional acrylic crown. The abutment part of the implant was prepared before crown cementation. The ceramic permanent crown was placed after three months. A health implant scale was chosen to evaluate implant success. A periapical standard $X$-ray was taken immediately upon bonding of the temporary crown as well as after one year of loading. Proximate bone loss was measured using Canvas 9 (ACD, 2004).

Results: No implant was lost; thus, the one-year implant survival was $100 \%$. Optimal survival was $93.6 \%$. A statistically significant mean marginal bone loss was observed between baseline and 12 months (mesial: $1.06 \pm 0.55 \mathrm{~mm}$; distal: $1.05 \pm 0.53 \mathrm{~mm}$ ).

Conclusion: A high one-year survival rate was documented for management of congenital missing maxillary lateral incisors using immediately loaded mini-implants, and these implants therefore provide a good alternative treatment option.
\end{abstract}

(Int Dent Res 2012;2(1):27-32)

\section{Introduction}

Various studies have documented the successful osseointegration and long-term function of prostheses supported by single-tooth implants $(1,2)$. The single-tooth implant has therefore become a common treatment alternative for the replacement of congenitally absent maxillary lateral incisors (3). In addition to achieving high survival rates, this type of restoration leaves the adjacent teeth untouched. If an implant is to be used to replace an absent maxillary lateral incisor, the buccolingual and mesiodistal thickness of the alveolus must be adequate to allow for appropriate implant placement. Unfortunately, without eruption of the permanent lateral incisor, the osseous ridge in 
this area is typically deficient (4), and lateral incisor sites are typically between 5 and $7 \mathrm{~mm}$ mesiodistal. Historically, the use of standard-diameter implants was common in implant treatments, but the lack of interdental space led to unfavorable aesthetic results. Recently, the use of small-diameter implants or platform-switched implants has been shown to have a positive effect on the treatment outcome $(5,6)$.

Smaller-diameter implants, which are called mini-dental implants (MDIs), are generally 1.8 to $3.30 \mathrm{~mm}$ in diameter (7). The main application of MDIs was previously to support provisional restorations during the healing time in preparation for conventional standard implants (8). Today, these implants are used in cases of an inadequate interdental space (9). The design of MDIs offers several advantages, including fewer surgical interventions and the opportunity for immediate implant loading (10). Linkow was the first to introduce the idea of immediate loading (11). Misch described two types of immediate loading: functional and non-functional occlusal loading. Non-functional immediate restoration of the implant prosthesis is performed in patients who are partially edentulous and is delivered with two weeks of implant insertion with no direct occlusal load (12).

The aim of this study was to evaluate the treatment outcome of immediately restored (oneweek) MDIs with a diameter of $2.5 \mathrm{~mm}$ one year after they were used to rehabilitate congenitally absent maxillary lateral incisors.

\section{Materials and Methods}

This study was carried out in accordance with the Declaration of Helsinki and was approved by the local ethics committee of Damascus University.

\section{Patients}

Twenty-three consecutive patients ( 13 females, 10 males) with a mean age of 21.6 years (range: 16-38 years) were included in this study. A total of 30 congenitally absent maxillary lateral incisors were replaced by MDIs. The following inclusion criteria were used:

- Congenital absence of maxillary lateral incisor

- No systemic disease

- Good oral hygiene

- Non-smokers

- Sites without previous bone augmentation

\section{I mplant surgery}

A total of $30 \mathrm{MDIs}$ (MS Implant; Osstem) were positioned using a one-stage surgical technique. The $2.5 \mathrm{~mm}$ implants were chosen because no space was available for wider implants. Because of space constraints, surgery had to be carefully performed with the guidance of a template to reduce the risk of damaging the adjacent teeth and to reduce the difficulties in the prosthetic phase due to poor positioning of the implant. All implant surgeries were performed under local anaesthesia only. An antibiotic ( $2 \mathrm{~g}$ augmentin) was administered $30 \mathrm{~min}$ before surgery. Each subject rinsed for $1 \mathrm{~min}$ with a chlorhexidine mouthwash. A crestal incision was made after the treatment area was sufficiently anaesthetised, and a full-thickness flap was elevated to reveal the bony architecture. A previously prepared surgical template was used to guide the drill for the initial osteotomy preparation; a $1.5 \mathrm{~mm}$ diameter drill corresponding to the length of the implant to be placed was used. A second drill with a $1.8 \mathrm{~mm}$ diameter finishing drill was then used, and one-piece $2.5 \mathrm{~mm}$ implants were inserted. The flap was closed with synthetic sutures (Vicryl 4.0; Johnson \& J ohnson/Ethicon, Somerville, NJ). Figure 1 shows a patient who was treated with an MDI.

\section{Prosthetic procedure}

Immediately following implant placement, minimal preparation was performed as necessary on the abutment to ensure adequate clearance on the facial surface to achieve an aesthetic temporary restoration and occlusal clearance. Provisional restorations were fabricated from temporary acrylic resin (J et Acrylic; Lang Dental, USA). The provisional restorations had no centric or eccentric occlusal contact points. The patient was seen at one week postoperatively, at which time the sutures were removed. After polishing, provisional restorations were cemented. After a healing phase of three months, the abutments were prepared with a gingival curettage bur (5878K-016; Brassler, Savannah, GA) and an impression was taken with vinyl siloxane impression material (CharmFlex; Dentkist, Inc., South Korea). All crowns were porcelain-fused-to-metal crowns and were fabricated using definitive restorations adjusted to have slight occlusal contacts in centric occlusion. Figure le shows the prosthesis after one year.

\section{Post-loading assessment}

A health scale for dental implants (13) was used to summarise the implant data.

\section{Bone loss}

Intra-oral radiographs were taken using the periapical long-cone paralleling technique. The film holder was attached to the film. The position of the 
film was recorded using the film bite-block to ensure that the second radiograph at 12 months was taken from the same angulations as the baseline film. All radiographs were taken with $\mathrm{E}$ speed Kodak film (Rochester, NY) and exposed using the same X-ray unit (ORIX-70; Ardet Srl, Buccinasco, Italy) with exposure factors of $70 \mathrm{kVp}, 8 \mathrm{~mA}, 0.144 \mathrm{~kW}$, and 0.325 -s exposure time. Figure If shows a baseline radiograph, and Figure $1 \mathrm{~g}$ shows a radiograph at the 12-month follow-up. All films were processed using an automatic machine (Velopex, Extra-X; Medivance, Harlesden, London, UK). The peri-apical films were scanned using a black and white translucent scanner; the radiographic images were standardised at 1200 dots per inch (d.p.i) and magnified approximately $800 \%$. Subsequently, lines and reference points were traced using Canvas 9
(Canvas, version 9.0.4; ACD System International, Inc.). Each image was calibrated using the known length of the fixture part (10 or $13 \mathrm{~mm}$ ). Periimplant crestal alveolar bone loss was measured along vertical planes in the traced radiographs. The distance between the implant apex and the first bone-to-implant contact was used as the measure of the vertical bone level (VBLE). Vertical bone losses (VBLO) were calculated by subtracting the corresponding bone levels at the temporary restoration cementation visit (baseline) from bone levels at the 12-month follow-up. Vertical bone losses were measured in millimeters at both the mesial and distal surfaces of each implant. Measurements of mesial and distal bone losses were made to $0.1 \mathrm{~mm}$.

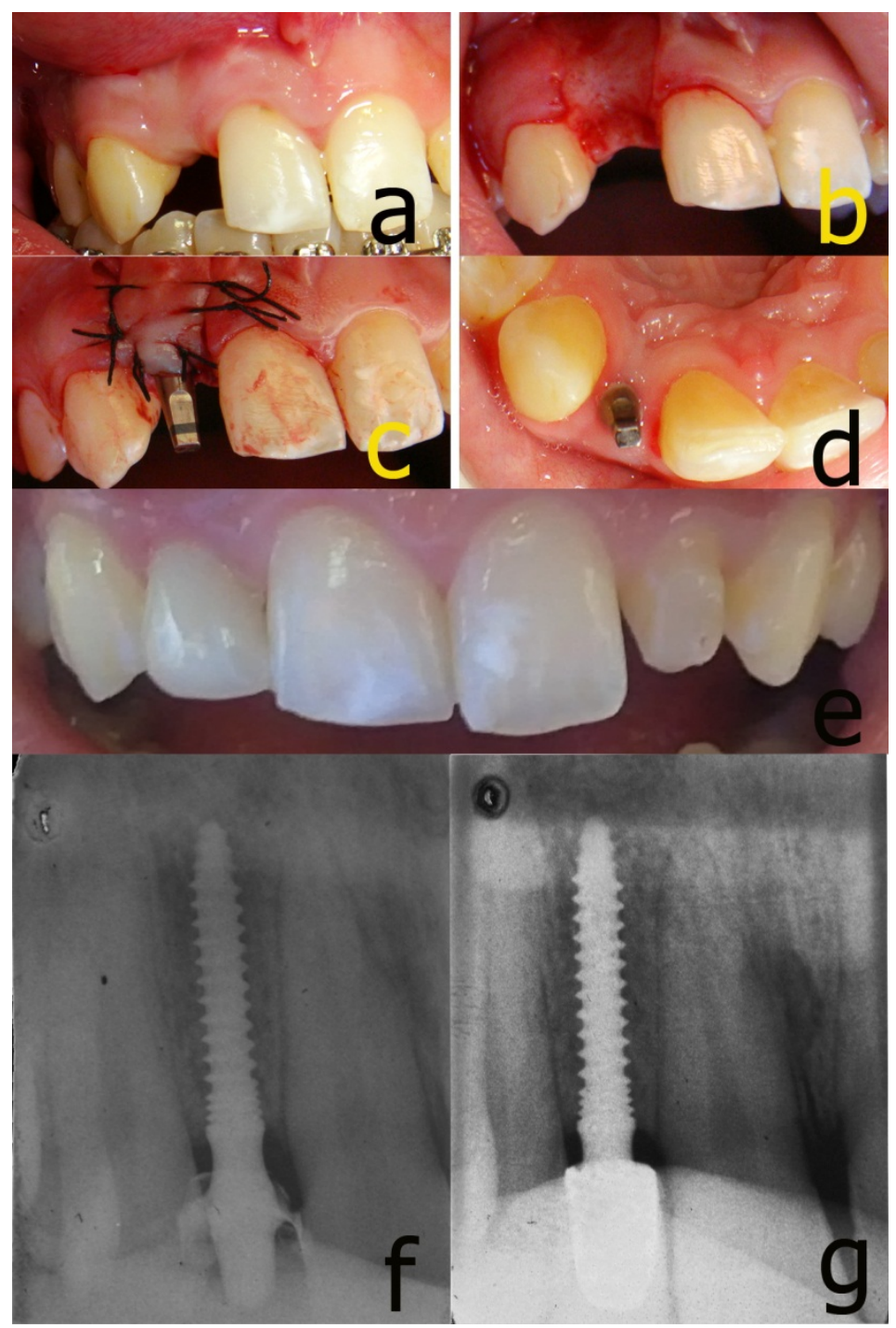

Figure 1. (a) Congenital absence of upper lateral incisor; (b) Flap reflection; (c) Sutures; (d) Occlusal view of MDI ; (e) Prosthesis after one year; (f) Baseline radiograph; (g) 12-month follow-up radiograph. 


\section{Outcome measures}

The following outcome measures were included:

One-year implant survival

Peri-implant marginal bone loss

\section{Statistical analysis}

Marginal bone loss was evaluated after 12 months of loading, and the results were presented as mean and standard deviations. The correlation between the marginal bone level at baseline and the marginal bone loss after 12 months was analysed by means of the Pearson correlation analysis after testing the linearity assumption.

\section{Results}

All 23 patients were available for the one-year follow-up. No implant was lost; thus the one-year implant survival was $100 \%$. Optimal survival was $93.6 \%$. A statistically significant mean marginal bone loss was observed between baseline and 12 months (mesial: $1.06 \pm 0.55 \mathrm{~mm}$; distal: $1.05 \pm$ $0.53 \mathrm{~mm}$ ). A total of $6.7 \%$ of the implants were characterised by a bone loss of $2 \mathrm{~mm}$ or more. Figure 2 shows the peri-implant marginal bone loss after 12 months.

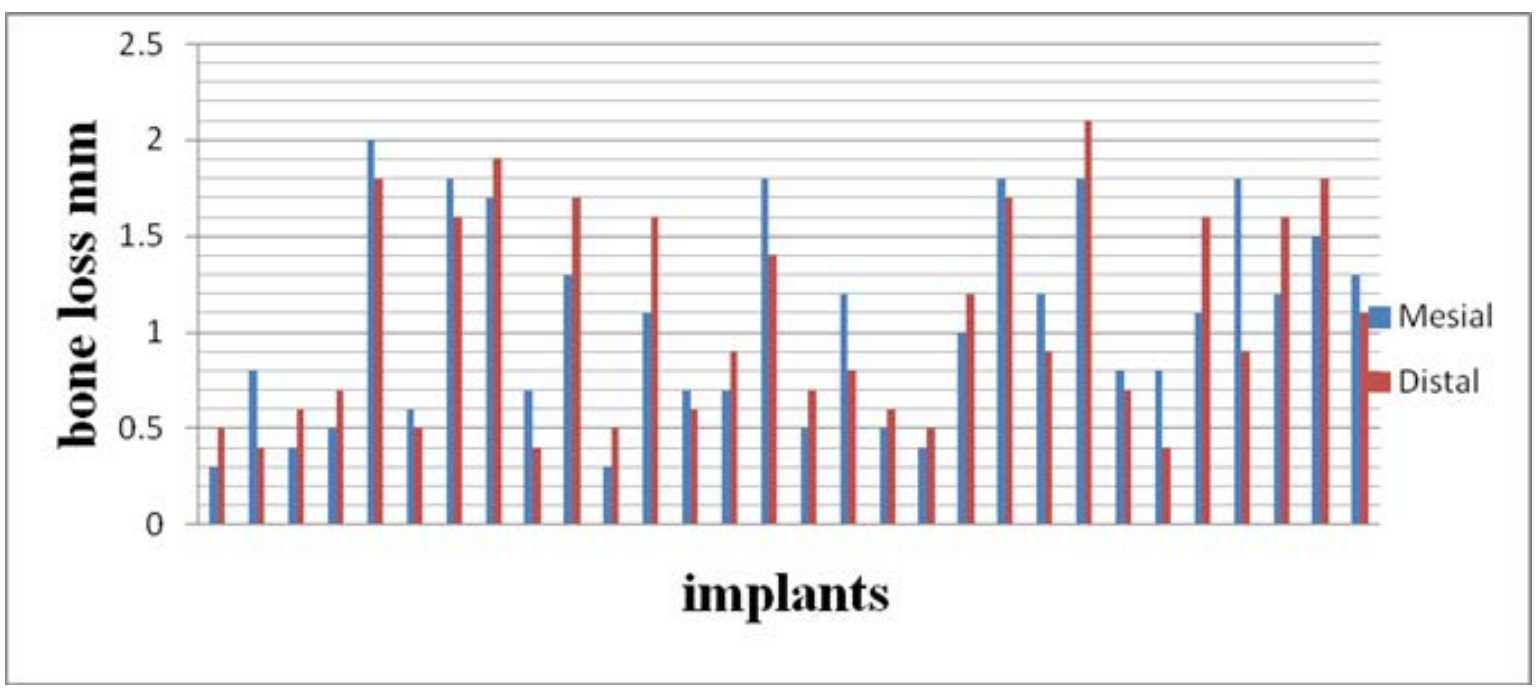

Figure 2. Peri-implant marginal bone loss after 12 months (30).

\section{Discussion}

The present study focused on the treatment outcome of immediately restored one-piece singletooth implants with a diameter of $2.5 \mathrm{~mm}$ after one year. The one-year implant survival rate was $100 \%$, and the one-year implant optimal survival (success) was $93.3 \%$. The implant survival in the present study is comparable with the previously reported survival of immediately loaded single-tooth twopiece implants after one year of loading (14), and is also comparable with the five-year survival of $97 \%$ for single-tooth implants reported in a recently published systematic review (15). Treatment outcomes involving implants with a reduced diameter has previously been documented. In accordance with these results, a survival rate of $94.2 \%$ after a mean observation period of five years was found when conventionally loaded two-piece implants with a reduced diameter $(2.9 \mathrm{~mm}$; $3 \mathrm{i}$ Implant Innovation, Inc.) were used (16).

Treatment outcomes involving immediately loaded one-piece implants have also been reported previously. Implant survival rates of $94 \%$ after 10.2 months, $89.1 \%$ after 1 year, $100 \%$ after 17 months, $75 \%$ after 2 years, and $98 \%$ after up to two years of loading have been documented (17-21).

Treatment outcomes involving immediately loaded one-piece small-diameter implants for management of absent maxillary lateral incisors and mandibular incisors have been documented previously. A survival rate of $98 \%$ was reported after one year of loading of MDIs inserted to rehabilitate missing maxillary lateral incisors and mandibular incisors (10). A success rate of $100 \%$ after $23 \pm 3.4$ months of loading has also been documented; only eight implants were placed in maxillary lateral incisor sites (22). In a 2010 study 
by Balaji, a two-year retrospective study summarised the recorded observations from 11 subjects who received $2.4 \mathrm{~mm}$ diameter implants for restoration of single maxillary lateral incisors or mandibular incisors. One implant failed 10 months after loading, and the success rate was $90.9 \%$ (23). Finally, different loading protocols were applied. As a result, it is difficult to compare the results of the present study with those of the above-mentioned studies.

The mean marginal bone loss was $1.06 \mathrm{~mm}$ after 12 months, and loss of $2 \mathrm{~mm}$ or more occurred around two implants. Proussaefs and Lozada reported that the mean marginal bone loss of immediately loaded two-piece single-tooth implants was $1.05 \mathrm{~mm}$ after 12 months of loading (24). In a study by Van de Velde et al. on immediately loaded one-piece implants, only three of 12 implants were considered successful, showing a bone loss of 1.7 $\mathrm{mm}$ after two years of function (21). In a study involving 115 one-piece implants, a failure rate of $5.2 \%$ due to excessive marginal bone loss was observed (25). The mean peri-implant marginal bone loss was $2.1 \mathrm{~mm}$ after one year. A mean bone loss of $1.6 \mathrm{~mm}$ after 12 months of loading of MDIs (3 $\mathrm{mm}$ ) placed in the maxillary lateral and mandibular incisor area was observed, while $18 \%$ of the implants showed more than $3 \mathrm{~mm}$ of bone loss (10). Variations in the state of implantation sites (extraction/healed site bone augmentation) between the sample sites may explain the observed differences in bone loss in the Zembic study. Sohn et al. reported that mean marginal bone loss after 12 months of loading was $0.53 \pm 0.37 \mathrm{~mm}$ (22). In the present study, the amount of bone loss during the first year of loading did not exceed the acceptable level of bone loss defined previously (26).

\section{Conclusion}

A high one-year survival rate was documented when MDIs were used for management of congenital missing maxillary lateral incisors with immediate loading. These implants therefore provide a good alternative treatment option.

\section{Acknowledgments}

\author{
The authors deny any conflicts of interest \\ related to this study.
}

\section{References}

1. Mayer TM, Hawley CE, Gunsolley JC, Feldman S. The single-tooth implant: a viable alternative for single-tooth replacement. J Periodontol. 2002 Jul; 73(7):687-93.

2. Weng D, Jacobson Z, Tarnow D, et al. A prospective multicenter clinical trial of $3 i$ machined-surface implants: results after 6 years of follow-up. Int J Oral Maxillofac Implants. 2003 May-J un; 18(3): 417-23.

3. Reddy MS, O'Neal SJ, Haigh S, Aponte-Wesson R, Geurs NC. Initial clinical efficacy of $3-\mathrm{mm}$ implants immediately placed into function in conditions of limited spacing. Int J Oral Maxillofac Implants. 2008 Mar-Apr;23(2):281-8.

4. Kokich VG. Managing orthodontic-restorative treatment for the adolescent patient. In: McNamara J A, Brudon WI, editors. Orthodontics and dentofacial orthopedics. Ann Arbor: Needham Press; 2001. p. 423-52.

5. Rodriguez-Ciurana $X$, Vela-Nebot $X$, SegalaTorres $M$, et al. The effect of interimplant distance on the height of the interimplant bone crest when using platform-switched implants. Int J Periodontics Restorative Dent. 2009 Apr;29(2): 141-51.

6. Flanagan D, Mascolo A. The mini dental implant in fixed and removable prosthetics: a review. J Oral I mplantol. 2011 Mar; 37 Spec No: 123-32.

7. Shatkin TE, Shatkin S, Oppenheimer BD, Oppenheimer AJ. Mini dental implants for longterm fixed and removable prosthetics: a retrospective analysis of 2514 implants placed over a five-year period. Compend Contin Educ Dent. 2007 Feb;28(2): 92-9; quiz 100-1.

8. Ahn MR, An KM, Choi JH, Sohn DS. Immediate loading with mini dental implants in the fully edentulous mandible. Implant Dent. 2004 Dec; 13(4): 367-72.

9. Shatkin $T E$, Shatkin $S$, Oppenheimer AJ, Oppenheimer BD. A simplified approach to implant dentistry with mini dental implants. Alpha Omegan. 2003 Oct; 96(3): 7-15.

10. 1Zembic A, Johannesen LH, Schou S, et al. Immediately restored one-piece single-tooth implants with reduced diameter: one-year results of a multi-center study. Clin Oral Implants Res. 2012 J an; 23(1):49-54.

11. Linkow LI, Miller RJ. Immediate loading of endosseous implants is not new. J Oral Implantol. 2004;30(5): 314-7.

12. Misch CE, Hahn J, Judy KW, et al. Workshop guidelines on immediate loading in implant dentistry. November 7, 2003. J Oral Implantol. 2004; 30(5): 283-8.

13. Misch CE, Perel ML, Wang $\mathrm{HL}$, et al. Implant success, survival, and failure: the International Congress of Oral Implantologists (ICOI) Pisa Consensus Conference. Implant Dent. 2008 Mar; 17(1):5-15. 
14. Cornelini R, Cangini F, Covani U, Barone A, Buser D. Immediate restoration of single-tooth implants in mandibular molar sites: a 12-month preliminary report. Int J Oral Maxillofac Implants. 2004 Nov-Dec; 19(6): 855-60.

15. Jung RE, Pjetursson BE, Glauser R, Zembic A, Zwahlen M, Lang NP. A systematic review of the 5-year survival and complication rates of implantsupported single crowns. Clin Oral Implants Res. 2008 Feb; 19(2): 119-30.

16. Vigolo P, Givani A, Majzoub Z, Cordioli G. Clinical evaluation of small-diameter implants in singletooth and multiple-implant restorations: a 7-year retrospective study. Int J Oral Maxillofac Implants. 2004 Sep-Oct; 19(5): 703-9.

17. Albrektsson T, Gottlow J, Meirelles L, Ostman PO, Rocci A, Sennerby L. Survival of NobelDirect implants: an analysis of 550 consecutively placed implants at 18 different clinical centers. Clin Implant Dent Relat Res. 2007 J un; 9(2):65-70.

18. Hahn JA. Clinical and radiographic evaluation of one-piece implants used for immediate function. J Oral Implantol. 2007;33(3):152-5.

19. Siepenkothen T. Clinical performance and radiographic evaluation of a novel single-piece implant in a private practice over a mean of seventeen months. J Prosthet Dent. 2007 Jun;97(6 Suppl):S69-78.

20. Sennerby L, Rocci A, Becker W, Jonsson $L$, J ohansson LA, Albrektsson T. Short-term clinical results of Nobel Direct implants: a retrospective multicentre analysis. Clin Oral Implants Res. 2008 Mar; 19(3):219-26.
21. Van de Velde T, Thevissen E, Persson GR, Johansson C, De Bruyn H. Two-year outcome with Nobel Direct implants: a retrospective radiographic and microbiologic study in 10 patients. Clin Implant Dent Relat Res. 2009 Sep; 11(3): 183-93.

22. Sohn DS, Bae MS, Heo JU, Park JS, Yea SH, Romanos GE. Retrospective multicenter analysis of immediate provisionalization using one-piece narrow-diameter $(3.0-\mathrm{mm})$ implants. Int J Oral Maxillofac I mplants. 2011 J an-Feb; 26(1): 163-8.

23. Balaji A, Mohamed JB, Kathiresan R. A pilot study of mini implants as a treatment option for prosthetic rehabilitation of ridges with suboptimal bone volume. J Maxillofac Oral Surg. 2010; 9:334-8.

24. Proussaefs $P$, Lozada J. Immediate loading of hydroxyapatite-coated implants in the maxillary premolar area: three-year results of a pilot study. J Prosthet Dent. 2004 Mar; 91(3):228-33.

25. Ostman PO, Hellman M, Albrektsson T, Sennerby L. Direct loading of Nobel Direct and Nobel Perfect one-piece implants: a 1-year prospective clinical and radiographic study. Clin Oral Implants Res. 2007 Aug; 18(4): 409-18.

26. Albrektsson T, Zarb G, Worthington P, Eriksson AR. The long-term efficacy of currently used dental implants: a review and proposed criteria of success. Int J Oral Maxillofac Implants. 1986 Summer; 1(1): 11-25. 